said that he had the greatest pleasure in adding a fow words in support of what had already been so well expressed, and he stated that the collection of the subscriptions by himself (the Conservative Whip) and the Liberal Whip (Mr. Burton Eills) was a very easy matter. He complimented the Lord Mayor on having secured the affections of the council by the cordial, affable, and absolutely correct manner in which his duties were discharged. The presentation committee learned that the Lord Mayor had already been prevailed upon to sit for his portrait in oils and therefore it was felt that another form of presentation would be more acceptable on this occasion. The inscribed bust was then unveiled amid loud applause. The Lord Mayor feelingly acknowledged the presentation.

\section{A CASE OF APPENDICOSTOMY.}

THE operation of appendicostomy is of recent introduction, for it was first performed less than five years ago, and in this country at least it has not received that amount of recognition which we think it deserves. Appendicostomy was introduced by R. Weir of New York; he was about to perform a cxcostomy for amœbic dysentery, and the appendix presented itself in the incision, and the idea occurred to him to attach the distal end of the appendix to the surface and to irrigate the colon through the lumen of the appendix. The operation was successful and the method has been widely employed since, especially in the southern parts of the United States. Some modifications have been introduced. Meyer sutures the base of the appendix to the parietal peritoneum. Tuttle of New York leaves the appendix unopened for four or five days, so that firm adhesions may form between its base and the peritoneum. J. A. Caisler of Memphis prefers to make an "inspection incision "at the upper part of the border of the right rectus in order to see if any abscess of the liver is present; he also applies a purse-string suture round the base of the appendix and two "guy ropes" of fine silk through the distal end of the appendix to relieve the tension during the subsequent irrigations. In nearly all the cases appendicostomy has been performed for dysentery, but C. B. Keetley has had much success in cases of very intractable constipation, where the appendix opening was employed to introduce an aperient daily. In the October number of the International Journal of Surgery Dr. J. B. Anderson of Yazoo City, Mississippi, has reported a case in which he performed the operation of appendicostomy for amœbic dysentery. A man, 35 years of age, had suffered from indigestion and diarrhœa for five years. The stools contained mucus, blood, and undigested food and the bowels acted from three to five times a day. He was very wasted and weak and no improvement followed ordinary treatment. Many amœbæ were found in the fæces. It was decided that appendicostcmy should be performed. When the abdomen was opened by an incision in the appendix region it was found that there was a contraction of the mesentery of the ileum about a foot from the cæcum. This was freed, so that the bowel was restored to its normal position. The appendix appeared to be healthy, though it was rather small. The meso-appendix was ligatured and the appendix was fixed in the upper angle of the abdo. minal wound by separate sutures through its peritoneal coat to the parietal peritoneum and to the aponeurosis, and the remainder of the wound was closed. On the fifth day the appendix was amputated slightly above the skin surface. Irrigations were commenced; each consisted of 15 grains of quinine dissolved in a quart of sterile water. In less than a week there was decided improvement, the temperature became normal, and the pulse-rate, which had been 50 , rose to 72 per minute. He was put on a liberal diet and he began to sit up on the twelfth day. The: irrigations were continued for 19 days and then the appendix was allowed to close, and in three weeks he was able to go out. His improvement was rapid and continuous, and his weight increased until he had gained nearly 30 pounds. When the report was written he was actively at work and he was able to take ordinary diet. The chief danger in these cases is that an abscess of the liver may be present as well and a hepatic abscess complicates amcebic dysentery in about 20 per cent. of the cases.

\section{AN EARLY OPPONENT OF BLEEDING.}

BLEEDING in small-pox, the plague, and measles, to mention no other serious ailments, used to be prescribed by many seventeenth-century physicians on the ground that the escaping blood carried away with it "the corruption " of the disease. In the case of small-pox it was contended "the corrupted blood being partly let out, it would be impossible that the afflicted persons should have so many of those deforming pustles, as they otherwise would have had." But, continues the unknown writer from whose "Errors of Phlebotomy Discovered" (1689) our quotation is taken, that blood-letting cannot be "performed without manifest hazard of the patient's life, experience and reason hath shewen, since so many great persons have fell meerly to save a handsome face." Bleeding, in fact, as this early opponent of it contends, tends to carry off the "vital spirits" which accompany the blood, but he agrees with the phlebotomists that though blood-letting may weaken it may also purify. Blood he believes to be locally corrupted, and like other writers of his age, such as Nicholas Culpeper, at times seems to argue as though Harvey's great discovery had never been made or had, at least, led to no deductions. "How shall we know," he asks, "when that vitiated parcel of blood, which we so much seek to remove, has taken up its abode in the inferior parts of the veins of the arm, and in the arteries tending thereto, that we may let it out?" This passage, though apparently admitting the fact that the blood circulates, seems to imply that blood is different in quality in different parts of the body. Later in his essay he seems to see his error here, and he closes with the sound conclusion, which he argues syllogistically, "Therefore to make an end of all, it appears, That the means used to let out bad blood, without removing the efficient cause thereof, is no direct method of healing."

Dr. George Dean, chief bacteriologist at the Lister Institute of Preventive Medicine, has been appointed Professor of Pathology in the University of Aberdeen, to fill the place of Professor D. J. Hamilton who recently resigned.

\section{MOTORING NOTES:}

THE OLYMPIA MOTOR EXHIBITION.

BY C. T. W. HIRSCH, M.R.C.S. ENG., L.R.C.P. LOND.

THE seventh exhibition organised by the Society of Motor Manufacturers and Traders opens at Olympia to-day (Friday) The whole of the immense hall, annexe, and spacious gallery are completely filled with the exhibits of over 300 firms, to enumerate which would be practically to compile a directory of the whole of the motor industry. In the main hall and annexe are the cars, while in the gallery tyres, accessories, and the thousand and one odds and ends that can be piled on to a car are to be seen. And this reminds me of a very powerful argument why a medical man should invest in a car, which was recently told me by a medical man's better half. " $\mathrm{Oh}$," said the medical man's wife, "if only my husband buys a car we will be relieved of all worry about Christmas and birthday presents ; there are no end of motor odds and ends, tyre testers, clocks, speedometers, rugs, horns, lamps, footwarmers, \&c., which will meet the case for years." 
In order to save the time of such confrères as may (and I hope many will) visit this show I went over it some days prior to the opening, and now append notes of some of the exhibits which appear to me to be worthy of the special attention of the medical motorist and the embryo medical chauffeur.

The so-called "valveless" engine, which has been adopted by the Daimler Co., is undoubtedly the feature of the show, and crowds thronged round Stand No. 54 to inspect Mr. Knight's bomb; certainly the Daimler Co. in taking up this invention have staggered the motoring trade. It looked as if the motoring profession were excited from the manner they discussed Mr. Knight's paper at the Royal Automobile Club. And yet the present owners of the mushroom valve machine need not, I think, give up or scrap their cars; they have done good work; I know mine have, and, what is more, I think they will continue to do so. Still, the new "Silent Knight" is a pretty piece of machinery. It consists of a cast-iron liner, which is the full length of the cylinder, and has ports for the inlet and exhaust gases cut in it; it moves up and down over the inverted piston and has a wide ring at the bottom to cover entirely the ports at the time of compression and explosion; these sleeves are operated by an eccentric shaft, and as both the sleeves and the cylinders are of cast iron and perfectly machined they work well together and there is neither fear of seizure nor of escape of pressure, though the lubrication is merely by splash. The combustion head is spherical and machined, so there is little likelihood of any deposit of carbon, a common cause of pre-ignition. The only point that struck me is that this engine comes rather late in the day; years ago valves were apt to stick or even fracture at the neck, and when they did so near the mushroom the latter was apt to drop nto the cylinder and indulge in a trial of strength with the piston, with the result that at the post-mortem of the motor a cracked piston and a lump of metal with many llats on it would be found. But now that the valves are made from hammered forgings and the guides are so well machined and true, valve troubles can really be said not to exist, and their cure by their suppression, though interesting, is not needed.

At all the Olympia shows, and I have attended them for the past five years, the Humber exhibits, in addition to being the object of great popular interest, have always attracted the medical motorist, and probably this year Stand No. 44 will decide many a medical man to take to an automobile. The new 8-h.p. is quite a novelty and reminds one of the highly successful and still running ten-year-old 5- and $6 \frac{1}{2}$-h.p. cars produced by this firm. The engine has two cylinders, and what strikes the eye on raising the bonnet is its compactness and the absence of pipes. Dual ignition is fitted. Lubrication is on the automatic forced feed system, actuated by a small gear-driven pump, which obtains its supply of oil from a large pump situated in the bottom of the crank case. Thus all encumbrances on the dash board are done away with, the crank case is filled with oil, an oil level indicator shows how much is there, and the pump supplies the lubricant to all the bearings. This car is only supplied as a two-seater, and as such with a hood and front shield it appears to be an excellent car for a professional man, and at the price-£215-hard to equal. The other Humbers which will entice the practitioner are the 12-h.p. and the 15-h.p. The former is a late type, slightly improved, of the 10-12. h.p., of which I gave a full account in THE LANCET of April 11th of this year. The landaulette body on the car exhibited has been especially fitted for the profession and everything a medical man is likely to require seems to have been provided for, but Messrs. Humber write that they would esteem any suggestions of how a carriage of this description should be fitted up best to meet a medical man's requirements, so if any reader can think of anything left out perhaps he will communicate with Messrs. Humber.

The Rover Co. are at Stand 57, and in addition to their little 6-h.p. car, which was fully described in THE LANCET of August 22nd and which I really think is an ideal car for a doctor, they show among others a new four-cylinder 15-h.p. car. It looks a likely machine for a man who wants a car capable of carrying four and powerful enough for a landaulette body. Four semi-elliptical springs are employed to support the frame, and this car has an arrangement that should silence the complaint of Mr. Knight about tappet valves being noisy, as here they consist of two plungers, one telescoping into the other, with a spring between them; the upper plunger has a fibre washer and the lower plunger has a ball which rests upon the cam on the eccentric shaft. The usual Rover disc clutch is fitted, but an outside adjustment is provided for the compression spring, and the clutch can be dismantled without having to interfere with any other part, which is really a great advantage. Ignition is by coil and accumulator, and the contact maker is bevel driven by a vertical shaft, and another shaft is provided for driving the magnets in case one is required. Three forward speeds are provided, the top being direct. Water circulation is by a turbine form of pump, and by an arrangement of flanges the stream is thrown between the cylinders and about the exhaust valve pockets. A positive rotary pump is employed for the lubrication. The carburettor is of the Rover type, and by means of a floating piston with ports allows more air to pass as the speed of the engine increases. The live axle is well supported and the brakes seem suffciently powerful.

The Wolseley Tool and Motor Car Co. are well known to the veteran medical automobilist, as many have used their little 6-h.p. cars with pleasure and success. They were noisy and occasionally their cranks fractured, but for every. day work and general reliability they are unequalled. In fact, I have one now, nearly six years old, but it still does my daily round, and what is more did a journey to Bexhill and back in a day quite recently, so I can with great confidence advise the would-be buyer to halt and closely inspect the cars, which are shown on Stand 47. The 10-h.p. twocylinder with a short wheel base makes an excellent twoseater, or with the 8 feet 8 inches wheel base it answers for either a town carriage or a four-seater. Ignition is by accumulator and coil. The clutch is a leather-faced cone and connected to the gear box by a universally jointed shaft, while the power is transmitted to the live back axle by a propeller shaft and bevel gearing. Water circulation is by thermo-syphon with an additional air draught by a fan behind the multitubular radiator. The carburettor is of the automatic type. The weight of the chassis is between 12 and 13 hundredweights, so this car should be light on tyres. The company likewise show a light four-cylinder 14-h.p. car, the chassis of which comes out at 14 hundredweights. This is very flexible in traffic, very silent, and is fitted with gate change, magneto ignition, pump lubrication, thermo-syphon water circulation, with extra large water pipes. A new carburettor, giving increased efficiency, has been adopted, and the foot brake on their recent models has been enlarged in diameter and has increased wearing surface.

The Star Engineering Co. has on Stand 95 two very suitable cars for medical men. They are a 10-h.p. two-cylinder and a 12-h.p. four-cylinder. Ignition is by high tension magneto; three forward speeds and a reverse with a gate change are provided, and the drive is by a cardan shaft to a live axle, the driving pinion is carried in ball bearings, and a Dubrille type of lubricator is fitted.

Messrs. Mors also show a chassis of a light 10-h.p. fourcylinder cardan-shaft-driven, which at the price-£260-is certainly worthy of the consideration of those in search of a four-cylinder. The four cylinders are cast en bloc and the valves, pump, and high-tension magneto are all on the near side. The carburettor has two jets, the smaller working when the engine runs light; as the throttle is opened this is cut out and the larger one comes into play. The clutch is of the metal to metal kind and lubrication is by pressure off the exhaust.

Among other French makers who turn out suitable cars for the profession the Darracq must not be omitted. They show an 8-10-h.p. two-cylinder two-seater at £175,"a 10-12-h.p. two-cylinder, and a 14-16-h.p. four-cylinder, which latter can be had either with a side entrance tonneau body or as a car for town visiting with a brougham body. These are on Stand 73

On the left, near the Addison-road entrance, at Stand 76, Messrs. Alldays and Onions show their own all-English cars the two-cylinder model has a 10-h.p. engine and can be had either as a two- or four-seater, while their 14-h.p. has a fourcylinder engine. Semi-elliptic springs are employed for the suspension and the rear ones are hinged to the frame, so that they take the torque as well as transmit the drive to the road wheels. The valves are all on one side, on which is also the carburettor, which is pressure-fed and has a Bowden wiretickling device brought through near to the starting handle. The radiator is of the gilled tube variety and a pinion-driven 
water pump maintains the flow of water. Forced-feed lubrication is provided. Ignition is by battery and coil but there is a bracket on the crank case to receive a magneto which can be driven by a continuation of the pump spindle. A coned leather-face clutch transmits the power to the gearbox and the cardan shaft has a universal joint of the star type at each end. The price for the two-cylinder is £210.

The De Dion Bouton Co. have always specially catered for the profession, and very properly their cars are held in great esteem among us; in fact, I believe over 400 medical men in this country drive De Dions. Their two-seater is an especially smart turn-out. For 1909 they are putting three single-cylinder models on the market, an 8-h.p. fitted with their patent expanding clutch gear, an 8-h.p. with sliding pinion gear and pedal-operated clutch, and a 9-h.p. with double sleeve-type gear and a similar clutch. They all have the cardan-driven live axle, and on the new 8-h.p. the transmission is through a leather-faced cone clutch, and the gearbox is combined with the differential casing.

The Argyll Motor Co. have on view their new 12-14-h.p. Argyll, the feature of which is that the engine and gear-box are contained in one casting, the four cylinders are cast en bloc with all the valves on one side, the carburettor is on the other side, and passages cast between the cylinders lead the mixture to the valve pockets. Water circulation is by thermo-syphon. Lubrication is by a gear-driven pump. Three forward speeds are provided, the top being direct by means of a jaw-clutch, and the live axle is a very massive structure, the central casing having neither a horizontal nor vertical joint, the lid being large enough to permit of removal of the crown wheel. Their other model was described in The LanceT of May 30th.

On Stand 43 the Vauxhall Motor Co. show specimens of their manufacture; they are all four-cylinder 20-h.p., but give 23 on the brake. Their lubricating system is most excellent. At the rear end of the crank case there is an oil pump and by a plunger pump oil is forced into the main bearings and through the hollow crank shaft into the big-end bearings of the connecting rods. The inlet and exhaust valves are mechanically operated and arranged on one side of the cylinders and the cam shafts are driven by spur gearing at the front end of the engine. The valves are hammered from machined forgings and both the inlet and exhaust are interchangeable. The clutch is of the internal metal to metal cone type and the power is transmitted from the gear box to the back axle by a propeller shaft with universal joints at either end.

A car that took my fancy was the Adler, shown by Messrs. Morgan at Stand 138 in the annexe. It is a two-cylinder 7-h.p. vertical engine fitted with magneto ignition, but an accumulator working independently can easily be added. The inlet valves are mechanically controlled and the valve rods are adjustable, so that if any wear does take place they can be adjusted with extreme accuracy and without any trouble. An automatic spray carburettor is used. The clutch is of the metal cone type, and, which is an advantage, it can be taken out without disturbing the gear box. Three speeds forward and the usual reverse are provided; the top speed is direct. Transmission is by cardan shaft to a live axle. The cooling water is circulated by a pinion-driven pump, and a pump is likewise employed for lubrication. The brakes are of the usual kind, one on the driving shaft and internal expanding ones on the back wheels. I understand that with an English "Morgan body" the car is sold at $£ 180$, and at that price it seems worthy of the consideration of a medical man in search of a vehicle.

A great many people advocate the four-cylinder car; it is of course quieter, and if of not over, say, $14 \mathrm{~h}$. p., and made with a light body, not very extravagant in regard to tyres, provided that sufficiently large ones are fitted, and prominent among this class of car is the Sunbeam, manufactured by the Sunbeam Motor Car Co., and shown on Stand 46. The frame is of pressed steel; the cylinders are cast and set separately upon the crank chamber. All the valves are on one side and lifted by one cam shaft, which is-and this is an excellent feature-formed solid with its eccentrics. Ignition is by high-tension magneto, and the only criticism I have to make is that I do not like a magneto driven, as theirs is, by a chain; gear driven is, I am sure, better. A very good point is that the crank shaft has five bearings. A leather-faced cone clutch is employed, the gear-box gives four forward and one reverse speed, and the drive from the countershaft to the road wheels is by chains which, as in al the cars made by this firm, run in silent oil-tight cases. Cooling is by thermo-syphon and a very efficient radiator fan is provided. Adjustable ball thrust bearings are fitted to the steering wheel, so wear can be taken up and that decided unpleasantness, play in the steering wheel, absolutely done away with. Powerful brakes are provided, and those who desire a powerful well-built car, and do not mind giving about £425, will, I am sure, find this an excellent machine.

On Stand No. 10 Messrs. Jackson and Co. show their doctor's car. The frame is of pressed steel, machine riveted; the transmission is of the Renault type, with three forward speeds and a reverse, the high speed being direct. The back axle is especially strong, and though they only advise a 14-h.p. engine this axle is built for a 20-h.p. A leather-tosteel cone clutch is fitted and has a spring on the ball race. The radiator and tank are combined and fan-cooled. The pedals are of the push kind and the throttle control is above the wheel. The car is turned out with either a 8-9-h.p. De Dion engine or a two-cylinder 10-12-h.p. Aster or with the latter firm's four-cylinder 14-h.p. engine. A rear seat is provided for the chauffeur and the front seats are roomy and well protected by a front glass and hood. Side doors also. help to make this a really comfortable vehicle.

Now that the winter is approaching, the question of either heating the motor house or of running off the water every night has to be decided. If, as is advisable, distilled water is used, running the water off every cold evening is expensive ; in addition, if the car is wanted in a hurry it is a delay having to fill up and make sure that there is no air lock ; so on the whole, where possible, it is best to keep the temperature in the motor-house up, by either an electrie radiator or a protected gas stove and hot-water pipes. Sometimes this is not possible and then the Norton motor stove, which is on view in the gallery at Stand 186, can be employed. It is moveable, is made of planished steel and plated fittings, and costs, according to size, from $15 s$. to $20 \mathrm{~s}$. These stoves burn a patent fuel and are, I understand, absolutely safe and are allowed by the various insurance companies.

On Stand 259 the Continental Tyre and Rubber Co. show their latest all-rubber three-ribbed non-skid covers. These tyres have not only a very smart appearance, but actually do resist any tendency to skid on wet or greasy roads and in addition are markedly resilient; but those who require a really perfect non-skid should use for the back wheels this firm's red-black rubber steel-armoured cover these have been greatly improved and the studs are now so fixed that unless undue force is used they cannot become detached. Samples are also shown of their ordinary round treads and their square treads, as well as an extra strong inner tube, which is specially adapted for use with the threeribbed non-skid.

Among other tyres shown in the gallery are the products of the Dunlop Co., the Gaulois Tyres, Limited, and the Avon India Rubber Co.

It is of paramount importance that the brakes of a car should at all times be reliable and effective, and there is no doubt that accidents are constantly occurring through the failure of the brakes to act, so I am sure all motorists will be interested in a device shown on Stand 298, the Allen-Liversidge Front Wheel Brake. These are of the ordinary band type and work on drums mounted on the front wheels and fixed on the inner side close to the steering pivots. The actuating brake lever on one brake is connected by a steel cable to the actuating brake lever of the other and this passes over a pulley fixed on a sliding projection; when the brake is applied this pulley slides forward on its guide, so tightens the cable, and each band grips its drum. In addition, each flexible member before being attached to its respective brake lever passes round another pulley which is pivoted on an extension of the steering pivot and which is also capable of movement independent of the steering movement; thus a pull on the brake pedal not only actuates each brake simultaneously and evenly but in addition checking and steering can be done at the same time absolutely independently of one another, as the flexible member slides over the pulleys and automatically adjusts itself to the altered position of the wheels without affecting the action of the brake. One of the great advantages that will 
result from the employment of these brakes is that they will take the place of the popular but tyre and differential gear wearing differential brake, a brake that does cause severe and unnecessary strain on the driving tyres, and in addition however suddenly they may be applied there is no danger of side slip. I was so impressed with the idea of this front wheel brake that I accepted Mr. Liversidge's invitation to test them. It was luckily an ideal day for such an investigation. It had just rained and the Woolwich-road from the Free Ferry to Greenwich Hospital was like a skating-rink, but though we flew over the tram lines and kept on pulling up dead sharp never once did we skid when the front brakes were used, but, with those on the driving wheels it was different. In addition, however fiercely applied, they always stopped the car gently ; in fact, there was no jerk, it was like settling into a soft air cushion. Personally, I have always rather objected to brakes worked by cables, but in this case, as they work over pulleys and the cables are sufficiently stout, there seems no likelihood of their fraying, and as medical men have so frequently to stop and as these brakes can easily be fitted to any car, I think they are certainly worthy of the attention of the medical motorist. On the car on which I was taken out the differential brake pedal was used for the front brake and the differential brake was done away with.

The Elastes Co. has in this gallery specimens of its "stuffings," which are excellent substitutes for pneumatic tyres and were referred to in THE LANCET of May 2 nd.

A useful device is shown by the Rotax Motor Co. on Stand 195, and if the cold weather sets in it will be a very welcome and almost a necessary accessory. This is a footwarmer which will go over the floor in front by the driver; it works in connexion with the cooling system and can easily be fitted on any car.

Medical men should not as a rule be pulled up for exceeding the speed limit, as if they transgress it is usually on account of an urgent case. Still, it is occasionally an adrantage to have a speed indicator on the car, and an excellent one is shown by Messrs. S. Smith and Son on Stand 185.

Messrs. Gramage have on Stand 199 a variety of most useful accessories for a car-lamps, horns, little electric lamps that can be fitted on to existing paraffin lamps and worked from the accumulators used for the ignition of the car, as well as all sorts of garments for the motorist.

On Stand 197 Messrs. Dunhill have a variety of handy things for the car as well as some practical coats. The coats are excellent for long drives, but I wish some firm could invent a garment as warm but which could be got into and out of a little more quickly by a medical man who drives an open car himself. It is a serious trouble to have to spend five minutes almost at the house of each patient in taking one's wraps on and off, the only other alternative being to drive with an ordinary overcoat and be always more or less half frozen. Messrs. Dunhill also show an auto tyre pump which certainly inflates tyres without labour.

There are a bewildering number of cars shown at the exhibition, and the increase in the number of small fourcylinder cars is particularly noticeable. High-tension magneto ignition is almost universally adopted. It is, of course, impossible to advise as to which is the best car for a medical man. With the experience $I$ have now had during my nearly ten years of motoring I am sure if $I$ had to start over again I would begin with a small single cylinder two-seater fitted with a light Cape cart hood and a mica front wind curtain, and judging from what $I$ saw at the show and the experience I have myself had, as well as the "petrol" talk of motor colleagues and friends, my own choice would rest between a small 6.h.p. Rover, the new 8-h.p. Humber, and a little two-cylinder Star among English cars. The De Dion are excellent, and though, of course, French, a complete stock of all spares are kept at the London branch. Among many others the Adler, Adams, and Alldays and Onions should be mentioned if a four-seater is desired, in addition to the larger cars made by the firms already named. I should inspect the two-cylinder Siddeley as well as their small four-cylinder, also the 10-h.p. and 15-h.p. Napier.

In this article $I$ have given a short account of most of these cars, as well as a few others which I think might interest members of the profession in need of a car. I am sure that if any of the small ones I have especially named be selected, and if the chosen car be properly looked after, the purchaser will never regret the step he has taken, and, in addition, will find it a joy as well as a saving of time and money.

\section{REPORT' ON SANITARY MEASURES IN INDIA FOR 1906-07.}

(Concluded from p. 1318.)

THE report finally enters more into detail on the several matters previously mentioned, including also certain other points not entered upon in the earlier portions. Thus, with respect to the meteorology of the year under review we find that the cold weather lasted longer than usual and that February and March were very wet months in Northern India, the seasonal rainfall being in very large excess. There was a delay in the setting in of both monsoon currents over by far the greater portion of the country, and the rainfall from June to September was in slight defect in the field of the Bay current, but was practically normal in the region usually served by the Arabian Sea current.

Turning now to consider more minutely the question of sickness and mortality during 1906, we see amongst facts noted that only 10 men were invalided for bilharzia hæmatobia in comparison with 23 in 1905, 71 in 1904, and 158 in 1903. The diminution in this disabling disease is a very satisfactory fact. Influenza gave a less admission-rate, in the proportion of $11 \cdot 4$ per 1000 for 1906 as compared with 14.2 per 1000 in 1905. Cholera, as we have seen, showed a considerable increase. The danger incurred by drinking milk or aerated waters in the native bazaars was exemplified by an outbreak at Meiktela, as it was found that the milk supplied to a certain billiard saloon came from a district where cases of cholera had occurred. The infected regiment was quickly moved into camp, thorough measures of isolation and disinfection were undertaken, and the disease at once was checked. Another instance of infected milk having been the source of the disease was shown at Secunderabad, the milk not having been boiled by the native contractors previously to its issue. Small-pox amongst the European troops is seen to have increased consistently during recent years, which is an unfortunate fact, as the disease amongst the larger body of native troops, on the contrary, has not shown augmented returns.

Intermittent fever shows a notable increase amongst all classes. Amongst the Europeans the admissions rose from 111 per 1000 to 176 per 1000 . The admission-rates were highest in both European and native troops in the Indus Valley group. A very satisfactory fact to be noted is the greater accuracy in the returns owing to the more frequent use by the medical officers of the microscope. A considerable portion of the sickness formerly ascribed to "ague" is now found to be due to a variety of causes, none of which have any connexion with malaria. These cases are now most frequently returned under the heading of "simple continued fever" and are shown as due (1) to constipation and indigestion, (2) to a too highly nitrogenous diet, (3) to exposure to the sun, and (4) to congestion of the liver. Soldiers recently arrived in the country are most liable to be attacked, whilst most of the admissions occurred not during the malarious season but during the hot dry months of the year. Respecting true malaria, the benign tertian parasite was most usually found, the rarest being the quartan and malignant tertian in the ratios of 80,13 , and 11 per cent. Only those cases are now returned as malaria in which malaria parasites are found in the blood, whilst a real reduction in the admission. rate has been effected by the "after-treatment" now given to patients in nearly all the stations, a nominal roll of these patients being kept at the station hospital, where the discharged patients are required to attend for from six weeks to two months to receive twice weekly a dose of quinine. This dose is from 10 to 20 grains, the larger being the most effective. This method has caused a large decrease in the number of readmissions for relapse. "Mosquito brigades" have been organised in nearly all the stations, the cantonments being mapped out into separate areas, and all collections of water treated with "earth oil " and "pesterine," both of which are cheaper than, and quite as effective as, petroleum. But it was found that in the great majority of instances little or no effect was produced on the mosquitoes and that quinine prophylaxis was the best system. Malta 